\title{
Research Paper: The Effects of Mindfulness-Based Training on Psychological Wellbeing and Emotion Regulation of Menopausal Women: A Quasi-exper- imental Study
}

\author{
Mohammad Sadegh Zamani Zarchi ${ }^{1}$ (D), Roghieh Nooripour ${ }^{2}$ (D), Ali Hosseinzadeh Oskooei ${ }^{*}$ (D), Gholam Ali Afrooz \\ 1. Department of Counseling, Faculty of Psychology and Education, Kharazmi University, Tehran, Iran. \\ 2. Department of Counseling, Faculty of Educational Sciences and Psychology, Alzahra University, Tehran, Iran. \\ 3. Department of Counseling, Faculty of Education and Psychology, Shahid Beheshti University, Tehran, Iran. \\ 4. Department of Exceptional Child Psychology and Education, Faculty of Psychology and Education, Tehran University, Tehran, Iran.
}

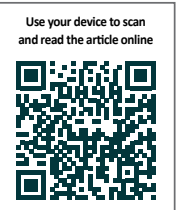

Citation Zamani Zarchi MS, Nooripour R, Hosseinzadeh Oskooei A, Afrooz GA. The Effects of Mindfulness-Based Training on Psychological Wellbeing and Emotion Regulation of Menopausal Women: A Quasi-experimental Study. Journal of Research \& Health. 2020; 10(5):295-304. http://dx.doi.org/10.32598/JRH.10.5.1669.1

: http://dx.doi.org/10.32598/JRH.10.5.1669.1

\section{(c) (i) \$}

Article info:

Received: 06 Mar 2019

Accepted: 16 Jun 2020

Publish: 01 Sep 2020

\section{Keywords:}

Menopause, Mindfulness, Psychological wellbeing, Emotion regulation

\section{A B S T RACT}

Background: Menopause is one of the most critical phenomena in women's lives, leading to emotional and behavioral symptoms in many cases. In this regard, this study aimed to determine the effectiveness of mindfulness training for menopausal women on psychological wellbeing and emotional regulation.

Methods: The research method, conducted in 2019, was quasi-experimental with a Pre-test-Posttest design and a control group. This study population included all menopausal women referring to Rasht City healthcare centers. A total of 28 women were selected using the convenience sampling method based on the study criteria and were randomly assigned to the experimental and control groups ( $n=14)$. Ryff's psychological wellbeing questionnaire (1989) and emotion regulation questionnaire (Gross and John, 2003) were asked to complete all participants. The experimental group received an 8-session mindfulness training and the control group did not receive any training program.

Results: The results of multivariate analysis of covariance showed that the Mean \pm SD scores of psychological wellbeing $166.47 \pm 18.94$ and emotional regulation $25.56 \pm 4.12$ in the experimental group increased significantly in the Post-test $(\mathrm{P}<0.05)$, i.e., $188.67 \pm 12.220$ for the psychological wellbeing and $37.02 \pm 5.12$ for the emotion regulation.

Conclusion: Mindfulness training is an effective way to improve menopausal women's psychological wellbeing and emotional regulation and it can be used to help these women by counselors and therapists.

\footnotetext{
* Corresponding Author:

Ali Hosseinzadeh Oskooei, MA.

Address: Department of Counseling, Faculty of Education and Psychology, Shahid Beheshti University, Tehran, Iran

Phone: +98 (936) 7408258

E-mail: hosseinzadeh.aliso@gmail.com
} 


\section{Introduction}

he role of women in families has positioned them as the health managers or $\mathbf{T}$ promoters of the overall health of the family members, especially children in developing countries whose lives are directly linked to their mothers' lives [1]. It is very critical to pay attention to the biological and psychological status of women. Women usually face specific problems caused by physiological conditions such as menopause throughout their lives. Menopause is a complex phenomenon involving a range of physiological and psychological changes in the life of middle-aged women [2]. The World Health Organization (WHO) has defined natural menopause as a permanent cessation of menstruation due to the loss of follicular ovarian activity or follicle decline. After 12 consecutive months of amenorrhea with no pathological or physiological cause, natural menopause is recognized [3].

Menopause affects all aspects of women's lives and sometimes severely threatens their quality of life during menopause. Similar to the rest of the world, the aging process in Iran has also increased, with about $7 \%$ of the population aged 40-65 years [4]. The major consequences of menopause and reduced levels of estrogen in women lead to a fairly wide range of physical and psychological problems [5] such as mood instability, depression, anxiety, sexual dysfunction, restlessness [6], and difficulties in social performance and other aspects of mental health [7]. Indeed, a significant proportion of menopausal women inevitably suffer from problems related to mental health [8], including psychological wellbeing reduction [9].

Several studies have shown that menopausal women have low psychological wellbeing, which can reduce their quality of life $[5,9,10]$. Psychological wellbeing has been defined as a state in which people realize their potential abilities $[11,12]$ and is closely linked to autonomy, positive relationships with others, life goals, and personal growth [12]. Also, psychological wellbeing plays a key role to reduce anxiety, depression, and other emotional problems $[13,14]$.

Emotion is one of the key aspects of psychological wellbeing for women. Regulation of emotions can play an important role in promoting psychological wellbeing [15]. Emotion regulation refers to the understanding of the emotions and the ability of behavioral control to achieve individual goals and situational requirements. A key feature of emotion regulation is the ability to diagnose and suppress feelings, manage emotions, and learn to empathize with others. The skills of emotional regulation play an important role not only in the optimal management of mood but also in the preparation of people to deal with problems sufficiently and to take appropriate decisions in life [16]. Emotion regulation, therefore, seems to be an important skill for everyone and can be an important part of the treatment of menopausal women in particular.

As regards the role of emotional regulation and, as a result, psychological wellbeing in the mental health and quality of life of menopausal women [11, 16], healthpromoting interventions focusing on psychological wellbeing and emotional regulation seem necessary for these women. Mindfulness-based therapies are among the most important interventions that have recently drawn considerable attraction. Mindfulness means maintaining a moment-by-moment awareness of thoughts, feelings, body sensations, and surrounding environment, through a gentle and nurturing lens. Mindfulness also involves acceptance, meaning that a person can pay attention to thoughts and feelings without judging them [17].

Mindfulness is one of the important factors in predicting psychological wellbeing and regulation of emotions. Mindfulness-based therapy affects not only emotional regulation but also increases psychological wellbeing through repeated exercises $[18,19]$ by focusing on emotions and accepting them. In this regard, studies have indicated that mindfulness training through nonjudgmental observation and mindful behavior would improve psychological wellbeing and psychological symptoms [20, 21]. Research has also shown that mindfulness training has a positive effect on improving the mood and quality of life of patients with chronic pain and their physical and psychological wellbeing [22].

Ghane et al. [23] suggested that awareness training in elderly women improved their subscales of personal wellbeing and mental health. Jenaabadi et al. [24] found that teaching mindfulness skills helped reduce job stress and increase the psychological wellbeing of female teachers. On the other hand, several studies have highlighted the effectiveness of mindfulness in improving the regulation of emotions [25]. In a study in patients with breast cancer, Norouzi and Hashemi [26] showed that mindfulness training was an effective factor in increasing emotional regulation in these patients [26].

In their research, Esmaily et al. [27] also showed that mindfulness training increased the regulation of cognitive emotions and mindful control of addicted people. Alem Dinati and Moheb [28] showed in a study of ob- 
Table 1. A summary of training sessions

\begin{tabular}{|c|c|}
\hline Session & Content and Activities of Each Session \\
\hline 1 & $\begin{array}{l}\text { The participants are asked to present themselves at first. In the second phase, they are given a brief overview of } 8 \text { ses- } \\
\text { sions and a general description of emotional regulation and psychological wellbeing. For homework, the participants } \\
\text { are asked to focus on their routine activities such as brushing or washing dishes on the same qualities as eating the } \\
\text { raisin. The Pre-test is carried out at the end. }\end{array}$ \\
\hline 2 & $\begin{array}{l}\text { The participants are encouraged to do the body scan exercise at the beginning of the second session and then discuss } \\
\text { their experiences with this exercise and their home practice. The difference between thoughts and emotions is then } \\
\text { discussed, with the idea that thoughts create emotions, not actual events. }\end{array}$ \\
\hline 3 & $\begin{array}{l}\text { The third session begins with talking about homework and the exercise of seeing and hearing. The participants are } \\
\text { asked to see and hear for } 2 \text { min in a non-judgmental manner during this exercise. Meditation and breathing follow this } \\
\text { exercise with mindfulness to body sensations. The 3-min breathing space practice consists of three steps: attention to } \\
\text { the exercise at the moment, breathing mindfulness, and body mindfulness. }\end{array}$ \\
\hline 4 & $\begin{array}{l}\text { This session begins with breathing mindfulness and body and mind sounds. Then, there will be a discussion of stress } \\
\text { responses and one's response to difficult situations and alternative behaviors. At the end of the session, mindful } \\
\text { walking is practiced. Home assignments are as follows: sitting meditations, body scanning, or one of the mindful body } \\
\text { movements and breathing space practice for } 3 \text { minutes (in an unpleasant event). }\end{array}$ \\
\hline 5 & $\begin{array}{l}\text { The participants are asked to perform sitting meditation at the start of the fifth session. The second phase of con- } \\
\text { scious body movements is then practiced. The homework for the next session is as follows: sitting meditation, 3-min } \\
\text { breathing space in an unpleasant event and new routine activity in a thoughtful way. }\end{array}$ \\
\hline 6 & $\begin{array}{l}\text { This session starts with the breathing space practice for } 3 \text { minutes. Participants talk in groups of two about previous } \\
\text { homework. The homework for the next session is choosing a combination of meditations based on personal prefer- } \\
\text { ence in an unpleasant event, the 3-min breathing space practice, and new routine activity. }\end{array}$ \\
\hline 7 & $\begin{array}{l}\text { It begins with a 4-dimensional mediation and an awareness of all that is currently in mind. The 3-min practice of } \\
\text { breathing space is then performed. The homework consists of a combination of meditation strategies that participants } \\
\text { prefer, a 3-min breathing space practice in an unpleasant event, and a new routine activity in a mindful way. }\end{array}$ \\
\hline 8 & $\begin{array}{l}\text { This session starts with body scans in mediation. The 3-min breathing space is then practiced and followed by a discus- } \\
\text { sion of how to cope with meditation barriers. The following questions are asked afterward: Did you meet your expec- } \\
\text { tations? Do you think your character has grown? Do you feel your coping skills have increased and want to continue } \\
\text { meditating on exercises? The Post-test is finally done. }\end{array}$ \\
\hline
\end{tabular}

sessive-compulsive patients that MBCT reduced negative cognitive emotion regulation strategies. Mehrinejad and Ramazan Saatchi [29] found that the practice of mindfulness simultaneously reduced women's depression, anger, and emotional dysregulation.

In general, there is little research about the importance of psychological wellbeing and emotional regulation during menopause, despite the high level of clinical efficacy for mindfulness intervention programs. The purpose of this study was to investigate the effectiveness of mindfulness training in menopausal women in Rasht City, Iran on their psychological wellbeing and emotional regulation.

\section{Methods}

This is a quasi-experimental study with a Pre-test-Posttest design and a control group. The study population included menopausal women referring to Rasht City healthcare centers.
Based on the inclusion criteria, and using the convenience sampling method, the authors referred to all health care centers and invited menopausal women to participate in the study.

The inclusion criteria for the participants were 4864 years old, complete menopause stop in the last 12 months with no medication or surgery. The exclusion criteria were hormone replacement therapy (using drugs to reduce menopause complications and any contraceptives and androgenic drugs), using herbal remedies to reduce menopause symptoms, diagnosis of mental and sexual disorders, using psychiatric or addiction drugs, having chronic and disabling physical illness (such as cancer, cardiovascular disease, apoplexy), experiencing adverse life events in the last 6 months. It should be noted that absence from more than one session and any occurrence of a psychosocial crisis or physical problem during the study were also considered as the exclusion criteria. 
The study participants were selected through a convenience sampling method and were randomly divided into the intervention and control groups. The control group was selected from the list of eligible individuals to prevent the exchange of information. They were administered the Pre-test and after 8 weeks, a Post-test. There was no intervention for the control group. The Pre-test evaluated 28 women who were eligible to participate in the study. This evaluation included establishing a good relationship with menopausal women and obtaining initial biographical data and completing questionnaires on psychological wellbeing and emotional regulation during a 1.5 -h session.

Menopausal women were then randomly allocated to the experimental $(n=14)$ and control groups $(n=14)$ and asked to attend the mindfulness training sessions at the Rasht mental health clinic (Table 1). The subjects were then given explanations for the rationale for treatment and the purpose of research. The consent forms have been completed and participants were assured that all their information would remain confidential. Eight training 1-hour sessions were performed once a week. After the completion of treatment sessions, both groups were retested in the Post-test stage. A summary of training sessions are provided here:

\section{Ryff's Psychological Wellbeing Questionnaire}

Ryff developed the questionnaire in 1989 and revised it in 2002. This scale of 54 items measures 6 aspects of wellbeing and happiness: autonomy, environmental mastery, personal growth, positive relationships with others, life purpose, and acceptance of oneself. The total score of psychological wellbeing is the sum of these 6 factors.
The responses to the scale are presented on a 6-point Likert-type scale ranging from 1 (strongly disagreeable) to 6 (strongly disagreeable) and some questions are scored in reverse order. Ryff [11] found an internal consistency of 0.91 for this scale using the Cronbach alpha values. Zanjani Tabasi translated the questionnaire in 2004, in which the Cronbach alpha for the entire scale was 0.94 and the subscales ranged between 0.63 and 0.89 .

The reliability of the scale in Mikaeli's research (2009) was reported to be 0.81 . The internal consistency (The Cronbach alpha) in the present study was 0.87 . In a study conducted by Joshanloo [8], the internal consistency (The Cronbach alpha) was 0.92 and the test-retest correlation coefficient for the entire scale was 0.76 and the subscales ranged from 0.67 to 0.73 , which are all significant.

\section{Grass \& John's Emotion Regulation Questionnaire}

This is a scale of 10 items that Gross and John developed in 2003 to measure the tendency of respondents to regulate their emotions. The questionnaire consists of two reassessment subscales (6 items) and suppression (4 items). Items are scored on a 5-point Likert scale from 1: Strongly disagreeable, to 5: Strongly disagreeable, and the total score, reassessment, and suppression subscales scores range from 10 to 50 and 6 to 30 and 4 to 20 , respectively. Studies have shown the reliability of the scale. The Cronbach alpha values for reassessment and suppression were 0.72 and 0.73 .

Also, the validity of the test-retest for both questionnaire components in three months was 0.69 . The reliability and validity of the scale were acceptable based on the

Table 2. The Levene's test results to investigate the homogeneity of within-group variance

\begin{tabular}{|c|c|c|c|c|}
\hline \multirow{2}{*}{ Variable } & \multicolumn{4}{|c|}{ Levene's test } \\
\hline & $\mathbf{F}$ & df1 & df2 & Sig. \\
\hline Reassessment & 2.050 & 1 & 28 & 0.133 \\
\hline Suppression & 2.424 & 1 & 28 & 0.151 \\
\hline Autonomy & 0.266 & 1 & 28 & 0.310 \\
\hline Environmental mastery & 0.137 & 1 & 28 & 0.165 \\
\hline Personal growth & 2.791 & 1 & 28 & 0.086 \\
\hline Positive relations with others & 0.495 & 1 & 28 & 0.128 \\
\hline Self-acceptance & 1.001 & 1 & 28 & 0.512 \\
\hline Purpose in life & 0.269 & 1 & 28 & 0.308 \\
\hline
\end{tabular}


Table 3. Mean \pm SD of Pre-test and Post-test scores of psychological wellbeing and its components in groups

\begin{tabular}{|c|c|c|c|c|}
\hline \multirow{3}{*}{ Components of Psychological Wellbeing } & \multicolumn{4}{|c|}{ Mean士SD } \\
\hline & \multicolumn{2}{|c|}{ Experimental } & \multicolumn{2}{|c|}{ Control } \\
\hline & Pre-test & Post-test & Pre-test & Post-test \\
\hline Autonomy & $26.2 \pm 3.45$ & $32.75 \pm 4.23$ & $25.91 \pm 3.07$ & $26.06 \pm 3.26$ \\
\hline Environmental mastery & $24.56 \pm 3.72$ & $30.57 \pm 4.64$ & $25.23 \pm 3.46$ & $26.14 \pm 3.27$ \\
\hline Personal growth & $24.21 \pm 3.66$ & $29.16 \pm 4.79$ & $26.13 \pm 3.49$ & $25.98 \pm 3.23$ \\
\hline Positive relations with others & $23.20 \pm 3.23$ & $31.68 \pm 4.76$ & $22.48 \pm 3.43$ & $23.56 \pm 3.67$ \\
\hline Purpose in life & $24.03 \pm 3.56$ & $20.14 \pm 4.25$ & $25.06 \pm 3.15$ & $24.44 \pm 3.72$ \\
\hline Self-acceptance & $24.46 \pm 3.28$ & $33.35 \pm 4.03$ & $25.23 \pm 3.34$ & $25.35 \pm 3.04$ \\
\hline Total & $126.86 \pm 11.94$ & $175.32 \pm 14.43$ & $127.42 \pm 11.69$ & $126.48 \pm 10.65$ \\
\hline
\end{tabular}

URE

internal consistency (with an alpha range of 0.6 to 0.81 ) and analysis of the main components using the rotation of the varimax [8].

The obtained data were analyzed using descriptive statistics (mean and standard deviation) and inferential statistics (Box test and multivariate covariance analysis) in SPSS V. 22. The significant level was set as less than (0.05).

\section{Results}

Based on the participants' demographic characteristics, $75 \%(n=21)$ were married and $25 \%(n=7)$ were divorced. In terms of education, $2.66 \%(n=4)$ were poorly educated (primary/secondary education), 67.85\% ( $n=19)$ had a high school diploma or equivalent, and $25 \%(n=7)$ were in higher education (bachelor/master/doctoral).

One of the assumptions of using covariance analysis is the normality of Pre-test data. To test this, the Shapiro-
Wilk test was used and since $\mathrm{F}$ was not significant at the level of $\alpha=0.05$, the assumption of normality was confirmed. Also, the suitability of the regression slope was authenticated. Therefore, the analysis of covariance was used to test the hypothesis.

Another assumption of using covariance analysis is within-group variance homogeneity in Pre-test data which was investigated using Levene's test. Since the Leveness $F$ value was not significant at the level of $\alpha=0.05$, withingroup variance was homogeneous. Also, the suitability of the regression slope was authenticated. Thus, the analysis of covariance was used to test the hypothesis (Table 2).

As shown in Table 3, the Mean \pm SD of psychological wellbeing components in the Pre-test and Post-test in the experimental group is $126.86 \pm 11.94$ and $175.32 \pm 14.43$. In the control group, the Pre-test and Post-test Mean \pm SD are $127.42 \pm 11.69$ and $126.48 \pm 10.65$.

Table 4. The Mean \pm SD of Pre-test and Post-test scores of emotion regulation and its components in groups

\begin{tabular}{|c|c|c|c|c|}
\hline \multirow{3}{*}{ Components of Emotion Regulation } & \multicolumn{4}{|c|}{ Mean士SD } \\
\hline & \multicolumn{2}{|c|}{ Experimental } & \multicolumn{2}{|c|}{ Control } \\
\hline & Pre-test & Post-test & Pre-test & Post-test \\
\hline Reappraisal & $12.23 \pm 3.76$ & $20.49 \pm 4.93$ & $13.65 \pm 3.83$ & $12.89 \pm 3.16$ \\
\hline Suppression & $10.66 \pm 3.45$ & $7.58 \pm 2.60$ & $11.16 \pm 3.56$ & $10.91 \pm 3.04$ \\
\hline Total & $25.56 \pm 4.12$ & $37.02 \pm 5.12$ & $23.42 \pm 3.55$ & $22.96 \pm 3.78$ \\
\hline
\end{tabular}


Table 5. Summary of the results of the multivariate analysis of covariance test for the scores of psychological wellbeing and emotion regulation in groups

\begin{tabular}{cccccccc}
\hline Index & Test & Value & F & df1 & df2 & P & Eta \\
\hline \multirow{3}{*}{ Model } & Piley effect & 0.376 & 6.563 & 1 & 26 & 0.001 & 0.394 \\
& Wilks' lambda & 0.538 & 6.563 & 1 & 26 & 0.001 & 0.394 \\
& Hoteling effect & 0.376 & 6.563 & 1 & 26 & 0.001 & 0.394 \\
& Roy's largest root & 0.376 & 6.563 & 1 & 26 & 0.001 & 0.394 \\
\cline { 3 - 6 } & Piley effect & 0.465 & 13.412 & 1 & 26 & 0.001 & 0.342 \\
& Wilks' lambda & 0.635 & 13.412 & 1 & 26 & 0.001 & 0.362 \\
& Hoteling effect & 0.892 & 13.412 & 1 & 26 & 0.001 & 0.374 \\
& Roy's largest root & 0.948 & 13.412 & 1 & 26 & 0.001 & 0.319 \\
\hline
\end{tabular}

According to Table 4, the Mean $\pm \mathrm{SD}$ of emotion regulation components in the pre-test and post-test in the experimental group are $25.56 \pm 4.12$ and $37.02 \pm 5.12$. In the control group, the pre-test and post-test Mean \pm SD are $23.42 \pm 3.55$ and $22.96 \pm 3.78$.

Based on the significance of all tests in table 5, the multivariate analysis of covariance is allowed. The results show that in one of the components of the dependent variables, there is a significant difference between the experimental and control groups. According to Eta results, the difference between the two groups is significant according to the dependent variables. Because of the interactions of the dependent variables, the difference based on the Wilks' lambda test is $46 \%$, which means that $46 \%$ of the variance is related to the difference between the two groups.

As shown in Table 6, there is a significant difference in the experimental and control groups between the mean scores of reassessments $(\mathrm{F}=10.54)$ and suppression $(\mathrm{F}=9.67)$. In other words, mindfulness has caused a major change in the experimental group's Post-test scores of emotion regulation components. There is also significant differences between the experimental and control groups regarding autonomy $(\mathrm{F}=12.53)$, environmental mastery $(\mathrm{F}=20.55)$, personal growth $(\mathrm{F}=11.24)$, positive relations with others $(\mathrm{F}=9.68)$, self-acceptance $(\mathrm{F}=7.54)$, and purpose in life $(\mathrm{F}=15.66)$. In other words, mindfulness has led to a major change in the experimental group's Posttest scores of psychological wellbeing components.

Table 6. Summary of the results of the multivariate covariance analysis test for the scores of psychological wellbeing and emotion regulation in the experimental and control groups

\begin{tabular}{|cccccc}
\hline Dependent variable & SS & df & MS & F & C \\
\hline Reappraisal & 234.45 & 1 & 234.45 & 10.53 & 0.001 \\
\hline Suppression & 291.87 & 1 & 291.87 & 9.67 & 0.001 \\
\hline Autonomy & 326.63 & 1 & 326.63 & 12.53 & 0.001 \\
\hline Environmental mastery & 352.82 & 1 & 352.82 & 20.85 & 0.001 \\
\hline Personal growth & 345.75 & 1 & 345.75 & 11.24 & 0.001 \\
\hline Positive relations with others & 386.61 & 1 & 386.61 & 9.68 & 0.001 \\
\hline Self-acceptance & 145.92 & 1 & 145.92 & 7.54 & 0.001 \\
\hline Purpose in life & 241.26 & 1 & 241.26 & 15.36 & 0.001 \\
\hline
\end{tabular}




\section{Discussion}

The results showed that mindfulness training plays an effective role in improving menopausal women's psychological wellbeing and emotional regulation. These findings are in line with the results of previous research aimed to identify the effectiveness of mindfulness training on negative strategies of cognitive emotion regulation in patients with obsessive-compulsive disorder [28], individual wellbeing and mental health of elderly women [23], professional stress, and psychological wellbeing of female teachers [24], depression, anger and emotion regulation of veterans' spouses [29], cognitive-emotion regulation and attentional control among addicted individuals [27], adolescent emotion regulation [25], medical and psychological symptoms and wellbeing [21], chronic pain in older adults [27], psychological wellbeing in female homemakers with secondary posttraumatic stress disorder [30], emotional and physiologic recovery from induced negative affect among women [31], perceived stress, psychological symptoms, emotion regulation of women [32], and cancer pain in metastatic cancer patients [33].

In explaining the positive effect of mindfulness training on wellbeing, it is important to note that mindfulness is a process in which menopause women learn to pay attention without judgment and avoid fighting their thoughts.

This makes women more responsive to stressful situations, including the menopause phenomenon and helps them manage their stress and negative emotions more effectively. Furthermore, mindfulness reduces anxiety and depression and thus improves mental health and psychological wellbeing [34]. On the other hand, mindfulness can affect all aspects of psychological self-acceptance, positive relationships with others, autonomy, environmental control, life purpose, and personal growth [35]. Mindfulness increases an individual's ability to accept himself by emphasizing the acceptance of unpleasant thoughts and emotions and eliminating evasive behaviors to avoid these inner experiences [36].

Furthermore, by promoting self-control and regulating the emotional state through constant mindful of emotional experiences, mindfulness brings happiness [36] and encourages people to develop empathic emotions and establish friendly relationships with others. According to Brown and Ryan [37], mindful people learn how to accept and manage their emotions and experiences and while analyzing all the critical issues, show the best pos- sible reaction and thus achieve autonomy and dominance of their environment. Also, mindfulness through these mechanisms leads to personal growth and purposeful life in individuals, and as a result, by influencing all the above dimensions, it increases psychological wellbeing.

It should be noted that one of the main reasons for the emergence of third-wave therapeutic approaches, in particular, psychological interventions, emphasizes the concept of acceptance and emotional components, neglected in previous therapies. Interventions based on mindfulness focus on improving the regulation of emotions. Sensitivity exercises change the perceptions of the people about the usefulness of coping strategies for dealing with thoughts and emotions. This is the process in which people are encouraged to experience more selfcontrol and mastery and thus more emotional self-regulation through the corrective experience and acceptance of negative emotions. In mindfulness, people gain more ability to control the impact of their thoughts and emotions by learning non-judgmental acceptance and can thus experience a wide range of negative thoughts and emotions without psychological distress. As a result of mindfulness, people will have more emotional stability in confronting intrusive thoughts that disturb their emotional regulation process and become a non-judgmental observer of what is happening so that their emotional regulation is not disturbed. Mindfulness uses a mechanism that proactively prevents emotional disturbance [32].

\section{Conclusion}

The present study showed that mindfulness training as a short-term method can simultaneously improve the psychological wellbeing and emotional regulation of menopausal women in Rasht City. This therapeutic approach can improve the quality of their lives and protect them when they face the problems of life and thus bring them a better life.

Concerning the limitations of research, the present study lacked a follow-up period to assess the long-term effectiveness of psychological well-being and emotional regulation training. Therefore, it is suggested that larger high-quality paths with a follow-up period support the results of this study. Also, the generalizability of the study and cultural differences should be taken into account since this research has been carried out on menopausal women in Rasht. In future studies, a larger sample size and subjects from different populations should be used to investigate the potential role of racial and cultural differences. Finally, the findings of this research suggest 
that early intervention is essential to provide menopausal women with a better life.

\section{Ethical Considerations}

\section{Compliance with ethical guidelines}

This study ethically approved (License No. 40/4-r/10) also All ethical principles are considered in this article. The participants were informed about the purpose of the research and its implementation stages; they were also assured about the confidentiality of their information; moreover, they were free to leave the study whenever they wished, and if desired, the research results would be available to them, also two free counseling sessions was offered to the control group.

\section{Funding}

This research did not receive any grant from funding agencies in the public, commercial, or non-profit sectors.

\section{Authors' Contributions}

Study design: Roghieh Nooripour, Ali Hosseinzadeh Oskooei, Gholam Ali Afrooz; Data collection and analysis: Mohammad Sadegh Zamani Zarchi, Ali Hosseinzadeh Oskooei, Roghieh Nooripour; Manuscript preparation: Roghieh Nooripour, Mohammad Sadegh Zamani Zarchi, Ali Hosseinzadeh Oskooei, Gholam Ali Afrooz; Approval of the final draft: All authors.

\section{Conflict of interest}

The authors declared no conflict of interest.

\section{References}

[1] Shifren JL, Gass MLS, NAMS Recommendations for Clinical Care of Midlife Women Working Group. The North American Menopause Society recommendations for clinical care of midlife women. Menopause. 2014; 21(10):1038-62. [DOI:10.1097/GME.0000000000000319] [PMID]

[2] Manson JE, Ames JM, Shapiro M, Gass MLS, Shifren JL, Stuenkel CA, et al. Algorithm and mobile app for menopausal symptom management and hormonal/non-hormonal therapy decision making: A clinical decision-support tool from The North American Menopause Society. Menopause. 2015; 22(3):247-53. [DOI:10.1097/GME.0000000000000373] [PMID]

[3] Chedraui P, Blümel JE, Baron G, Belzares E, Bencosme A, Calle A, et al. Impaired quality of life among middle aged women: A multicentre Latin American study. Maturitas. 2008, 61(4):323-9. [DOI:10.1016/j.maturitas.2008.09.026] [PMID]
[4] Mohammad K, Sadat Hashemi SM, Khalaj Abadi Farahani F. Age at natural menopause in Iran. Maturitas. 2004; 49(4):3216. [DOI:10.1016/j.maturitas.2004.02.006] [PMID]

[5] Erbil N. Attitudes towards menopause and depression body image of women during menopause. Alexandria J Med. 2018; 54(3):241-6. [DOI:10.1016/j.ajme.2017.05.012]

[6] Rouhbakhsh M, Kermansaravi F, Shakiba M, Navidian A The effect of couples education on marital satisfaction in menopausal women. J Women Aging. 2019; 31(5):432-45. [DOI:10. 1080/08952841.2018.1510244] [PMID]

[7] Parvin N, Kazemian A, Alavi A, Safdari F, Hassanpoor Dehkordi A, Hosseinzade S, et al. [The effect of supportive group therapy on menopause mental health (Persian)]. J Gorgan Univ Med Sci. 2007; 9(3):74-9. http://goums.ac.ir/journal/article-1-295-en.html

[8] Joshanloo M. Investigation of the contribution of spirituality and religiousness to hedonic and eudaimonic well-being in Iranian young adults. J Happiness Stud. 2011; 12(6):915-30. [DOI:10.1007/s10902-010-9236-4]

[9] Chiu HY, Pan CH, Shyu YK, Han BC, Tsai PS. Effects of acupuncture on menopause-related symptoms and quality of life in women in natural menopause: A meta-analysis of randomized controlled trials. Menopause. 2015; 22(2):234-44 [DOI:10.1097/GME.0000000000000260] [PMID]

[10] Ashok P, Apte GM, Wagh G, Joshi AR. Psychological wellbeing \& obesity in peri and post-menopausal women. Nat J Physiol Pharm Pharmacol. 2013; 3(1):97-101. [DOI:10.5455/ njppp.2013.3.97-101]

[11] Ryff CD. Target item. Psychological well-being and health: Past, present and future. Psychol Health. 2016; (1):726. https://www.francoangeli.it/riviste/Scheda_rivista. aspx? IDArticolo $=56129$

[12] Weiss LA, Westerhof GJ, Bohlmeijer ET. Can we increase psychological well-being? The effects of interventions on psychological well-being: A meta-analysis of randomized controlled trials. PLoS One. 2016; 11(6):e0158092. [DOI:10.1371/ journal.pone.0158092] [PMID] [PMCID]

[13] Romain AJ, Marleau J, Baillot A. Impact of obesity and mood disorders on physical comorbidities, psychological well-being health behaviors and use of health services. J Affect Disord. 2018; 225:381-8. [DOI:10.1016/j.jad.2017.08.065] [PMID]

[14] Rikkers W, Lawrence D, Hafekost J, Zubrick SR. Internet use and electronic gaming by children and adolescents with emotional and behavioural problems in Australia-results from the second child and adolescent survey of mental health and wellbeing. BMC Public Health. 2016; 16:399. [DOI:10.1186/ s12889-016-3058-1] [PMID] [PMCID]

[15] Kotsou I, Leys C, Fossion P. Acceptance alone is a better predictor of psychopathology and well-being than emotional competence, emotion regulation and mindfulness. J Affect Disord. 2018; 226:142-5. [DOI:10.1016/j.jad.2017.09.047] [PMID]

[16] Painter JM, Stellar JE, Moran EK, Kring AM. A multicomponent approach toward understanding emotion regulation in schizophrenia. J Clin Psychol. 2019; 75(1):178-89. [DOI:10.1002/jclp.22698] [PMID]

[17] Baer RA, Smith GT, Hopkins J, Krietemeyer J, Toney L. Using self-report assessment methods to explore 
facets of mindfulness. Assessment. 2006; 13(1):27-45 [DOI:10.1177/1073191105283504] [PMID]

[18] Emad S, Atashpour SH, Zakerfard MA. [Moderating role of the mindfulness and acceptance in predicting psychological wellbeing based on perfectionism in university students (Persian)] Posit Psychol. 2017; 2(3):49-66. [DOI:10.22108/ppls.2016.21540]

[19] Imani M, Karimi J, Behbahani M, Omidi A. [Role of mindfulness, psychological flexibility and integrative self-knowledge on psychological well-being among the university students (Persian)]. Feyz. 2017; 21(2):170-7. http:// feyz.kaums. ac.ir/article-1-3356-en.html

[20] Frank JL, Reibel D, Broderick P, Cantrell T, Metz S. The effectiveness of mindfulness-based stress reduction on educator stress and well-being: Results from a pilot study. Mindfulness. 2015; 6(2):208-16. [DOI:10.1007/s12671-013-0246-2]

[21] Carmody J, Baer RA. Relationships between mindfulness practice and levels of mindfulness, medical and psychological symptoms and well-being in a mindfulness-based stress reduction program. J Behav Med. 2008; 31(1):23-33. [DOI:10.1007/s10865-007-9130-7] [PMID]

[22] Morone NE, Lynch CS, Greco CM, Tindle HA, Weiner DK. "I felt like a new person." The effects of mindfulness meditation on older adults with chronic pain: Qualitative narrative analysis of diary entries. J Pain. 2008; 9(9):841-8. [DOI:10.1016/j.jpain.2008.04.003] [PMID] [PMCID]

[23] Ghane S, Asadi J, Derakhshanpour F. [Effect of mindfulness training on individual well-being and mental health of elderly women (Persian)]. J Gorgan Univ Med Sci. 2018, 20(1):71-6. http://goums.ac.ir/journal/article-1-3280-en.html

[24] Jenaabadi H, Pilechi L, Salmabadi M, Tayarani Rad A. [The effectiveness of training mindfulness skills in professional stress and psychological well-being of female teachers (Persian)]. Iran Occup Health. 2017; 13(6):58-69. http://ioh.iums. ac.ir/article-1-1574-en.html

[25] Metz SM, Frank JL, Reibel D, Cantrell T, Sanders R, Broderick PC. The effectiveness of the learning to BREATHE program on adolescent emotion regulation. Res Hum Dev. 2013; 10(3):252-72. [DOI:10.1080/15427609.2013.818488]

[26] Norouzi H, Hashemi E. [The efficacy of Mindfulness-Based Cognitive Therapy (MBCT) on emotion regulation among patients with breast cancer (Persian)]. Iran J Breast Dis. 2017; 10(2):38-48. http://ijbd.ir/article-1-628-en.html

[27] Esmaily S, Tabatabaee SM, Afrooz GA. [Effectiveness of mindfulness-based cognitive-behavioral therapy on cognitive - emotion regulation and attentional control among addicted individuals (Persian)]. Appl Psychol Res Q. 2015; 6(3):133-42. https://journals.ut.ac.ir/article_59109.html

[28] Alem Dianati F, Moheb N. [Effectiveness of mindfulnessbased cognitive therapy on reducing negative strategies of cognitive emotion regulation in patients with obsessive-compulsive disorder (Persian)]. J Instr Eval. 2018; 10(40):171-88. http://jinev.iaut.ac.ir/article_538065.html

[29] Mehri Nejad SA, Ramezan Saatchi L. [Impact of mindfulness- based cognitive therapy on depression, anger and emotion regulation of veterans' spouses (Persian)]. Iran J War Public Health. 2016; 8(3):141-8. http:/ /ijwph.ir/article-1-585-en.html
[30] Davis DM, Hayes JA. What are the benefits of mindfulness? A practice review of psychotherapy-related research. Psychotherapy. 2011; 48(2):198-208. [DOI:10.1037/a0022062] [PMID]

[31] Abedi F, Khademi Ashkzari M. [Mindfulness-based cognitive training on students' psychological well-being dimensions (Persian)]. J Psychol Stud. 2017; 13(3):111-28. [DOI:10.22051/psy.2017.9679.1140]

[32] Hoseinian S, Nooripour R, Afrooz GA. Effect of mindfulness-based training on aggression and empathy of adolescents at the juvenile correction and rehabilitation center. J Res Health. 2019; 9(6):505-15. [DOI:10.32598/jrh.9.6.505]

[33] Brown KW, Ryan RM. The benefits of being present: Mindfulness and its role in psychological well-being. J Pers Soc Psychol 2003; 84(4):822-48. [DOI:10.1037/0022-3514.84.4.822] [PMID]

[34] Omidi A, Shabanzadeh Fini M, Akbari H, Akasheh G. The effects of mindfulness-based stress reduction on emotional regulation and psychological well-being of Iranian veteran's homemakers with secondary posttraumatic stress disorder Arch Trauma Res. 2017; 6(4):82-6. [DOI:10.4103/atr.atr_4_18]

[35] Crosswell AD, Moreno PI, Raposa EB, Motivala SJ, Stanton AL, Ganz PA, et al. Effects of mindfulness training on emotional and physiologic recovery from induced negative affect. Psychoneuroendocrinology. 2017; 86:78-86. [DOI:10.1016/j. psyneuen.2017.08.003] [PMID] [PMCID]

[36] Cairncross M. The effects of an Internet-delivered mindfulness-based intervention on perceived stress, psychological symptoms, and emotion regulation [PhD. Dissertation] Windsor, ON: University of Windsor; 2019. https://scholar. uwindsor.ca/etd/7690/

[37] Poletti S, Razzini G, Ferrari R, Ricchieri MP, Spedicato GA, Pasqualini A, et al. Mindfulness-based stress reduction in early palliative care for people with metastatic cancer: A mixedmethod study. Complement Ther Med. 2019; 47:102218. [DOI:10.1016/j.ctim.2019.102218] [PMID] 
This Page Intentionally Left Blank 